\title{
Effective use of monitoring and evaluation systems in managing HIVIAIDS related projects: A case study of local NGOS in Kenya
}

\author{
Francis Nyaga Karani ${ }^{1}$, Walter Okibo Bichanga ${ }^{2}$, Charles Guandaru Kamau ${ }^{3 \text {, * }}$ \\ ${ }^{1}$ University of Nairobi, Nairobi, Kenya \\ ${ }^{2}$ Jomokenyatta University of Agriculture and Technology, Juja, Kenya \\ ${ }^{3}$ Kibabii University College, Bungoma, Kenya
}

\section{Email address:}

frncskarani@gmail.com (F. N. Karani),walter.okibo@yahoo.com (W. O. Bichanga), guandaruman@yahoo.co.uk (C. G. Kamau)

\section{To cite this article:}

Francis Nyaga Karani, Walter Okibo Bichanga, Charles Guandaru Kamau. Effective Use of Monitoring and Evaluation Systems in Managing HIV/AIDS Related Projects: A Case Study of Local NGOS in Kenya. Science Journal of Business and Management. Vol. 2, No. 2, 2014, pp. 67-76. doi: 10.11648/j.sjbm.20140202.13

\begin{abstract}
Close monitoring and evaluation during implementation leads to projects success. This study sought to determine how effectively the HIV/AIDS projects implemented by NGOs in Kenya are monitored and evaluated as laid down by the current National HIV/AIDS Monitoring and Evaluation Framework found in the Kenya National AIDS Strategic Plan 2009/10-2012/13 (KNASP III). The research considered several factors that affect the effective use of Monitoring and Evaluation by project managers in NGOs with HIV/AIDS projects in Kenya. These include lack of commitment by the project managers, incompetency on the use of the Monitoring and Evaluation systems by project managers, stringent donor requirements and capacity constraints of the NGOs. The data collected was analyzed using both quantitative and qualitative techniques. Measures of central tendency that is the mean, mode, and median were computed and interpreted. The data is presented using frequency distribution tables, pie charts and bar graphs. Relationship between various variables is established using simple correlation and regression. The researcher has used the software of Statistical Package for Social Sciences (SPSS) and the Ms-Excel. The data is also given in narrative form for explanation of situations. High ethical standards were maintained by the researcher. The study is significant in that has established the status of effective use of Monitoring and Evaluation in NGOs dealing with the HIV/AIDS pandemic in Kenya. This will contribute towards filling the present knowledge gap. The study will also form a basis on which other studies can be carried out.
\end{abstract}

Keywords: HIV/AIDS, Project, Monitoring and Evaluation, NGOs, Kenya

\section{Introduction}

The goal of the National HIV/AIDS Monitoring and Evaluation Framework is to guide compilation, analysis, use, and distribution of information that allows the tracking of progress made in response to HIV/AIDS and enhances informed decision-making [1]. The Framework provides a setting for addition of new fresh ideas on Monitoring and Evaluation and enhancement of indicators in tandem with efforts made by experts and organizations working on Monitoring and Evaluation of HIV/AIDS. The Framework further articulates the linkages, reporting relations and indicators used to determine inputs, outputs, outcomes, and impact of national response to HIV/AIDS [1].

While monitoring and evaluation is important in the management of projects, there is a tendency in NGOs not to effectively use the M\&E system available. The National Aids monitoring framework's review of KNASP II (2005/6-2009/10) points at poor use of the laid down frame- work.

\subsection{Objectives of the Study}

This study sought to achieve the following objectives:

1. To find out whether project managers in HIV/AIDS related NGOs in Kenya are effectively using monitoring and evaluation system as laid down in KNASP III M\&E frame work.

2. To find out the factors that affect the use of Monitoring and Evaluation by project managers in HIV/AIDS related NGOs in Kenya.

3. To come up with strategies that would encourage 
project managers to effectively use the M\&E systems.

\section{Literature}

\subsection{Introduction}

This section will highlight information from the various sources that relate to effective use of monitoring and evaluation by project managers managing HIV/AIDS projects in the local NGOs under the following headings: Project Management Tools, Monitoring and Evaluation, Monitoring and Evaluation in Africa, Monitoring and Evaluation in Kenya, HIV/AIDS in Kenya, National Aids Control Council.

\subsection{Project Management Tools}

The modern tools for managing project are scope, cost and schedule [2]. They are based on distinctive procedure and document controls, metrics, performance indicators and forecasting with ability to expose trends toward cost over use and/or schedule slippage [2]. Identifying those trends early makes them more agreeable to successful management.

The present vision tends to rely upon the idea of planning and control to recommend models and prescriptions as means to improve the ability of humans to manage complex worlds [3]. It emphasizes the role of project actors concerning the issues of time, cost and scope [4]. Project control is made up of Monitoring and evaluation (M\&E), which is a crucial component of any successful management activity [4]. Managers need the information generated to improve their management, and donors and stakeholders need results to guarantee accountability [4].

A research conducted in twenty six African countries in 2010 by members of the project management of the University of Quebec at Montreal to analyze the observed relationship between project management efforts, project success, and success criteria, suggests that project success is not sensitive to the intensity of project planning efforts but to the use of monitoring and evaluation tools which is an early indicator of a project's lasting impact [5].

$M \& E$ can support strong governance in many ways. First, the information it produces can be important for decision-making and the setting of priorities, particularly in the budgetary process [6]. Secondly, M\&E assists managers by bringing out the performance of ongoing activities at the project or sector levels, producing valuable information for planning new activities [6]. Thus, $\mathrm{M} \& \mathrm{E}$ is a management tool that promotes future learning and improvement; that is, management based on results [6]. Likewise, M\&E information can be used to measure the performance of organizations and institutional modification processes. Third, M\&E contributes to mechanisms that hold managers accountable for their performance [6].

\subsubsection{Monitoring and Evaluation}

Although the term "monitoring and evaluation" tends to get go together, they are, in fact, two different sets of organizational activities, interconnected but not the same [7]. Moreover, they can be looked at from the point of view of Evaluation. Evaluation can be formative. I.e. taking place during the life of a project or organization, with the intention of improving the strategy or way of functioning of the project or organization. It can also be summative (drawing learning from a completed project or an organization that is no longer functioning) [7].

Monitoring and Evaluation are common in that they both focus on efficiency effectiveness and the impact of the project. While efficiency tells you that the input into the work is correct in terms of the output, effectiveness measures the extent to which a development programme or project is achieving the specific objectives set for it, and impact informs you on the difference you have made to the problem situation were trying to deal with [8].

\subsubsection{Monitoring}

This type of evaluation is carried out while a project is going on, with the aim of improving its design and performance while in action [9]. An example found in the World Bank Technical Paper, 'Monitoring and Evaluating Urban Development Programs; A Handbook for Program Managers and Researchers' by Michael Bamberger [9], shows a monitoring study that, by way of quick survey, was able to conclude that the amount of credit offered in a micro credit scheme for artisans in Brazil was too little. The prospective beneficiaries were not participating because of the inadequacy of the loan size. This information was subsequently used to make a number of key changes in the project. Bamberger defines it as: "an inner project activity intended to give regular feedback on the advancement of a project, the challenges it is facing, and the effectiveness with which it is being implemented" [9].

Monitoring is also termed as the systematic collection and analysis of information as a project progresses along the lines of pre-set procedures and indicators which will eventually show the success or failure of the project [10]. It is meant at making the efficiency and effectiveness of a project or organization better based on targets laid down and activities planned during the planning phases of work. If done properly, it is a significant tool for good management, since it provides a helpful base for evaluation and enables you to know whether the resources at your disposal are adequate and are being well used, whether the capacity you have is sufficient and appropriate and whether you are doing what you planned to [10].

\subsubsection{Evaluation}

An evaluation studies the outcome of a project (changes in income, housing quality, benefits distribution, cost-effectiveness, etc.) with the aim of informing the design of future projects [10].

'Monitoring and Evaluating Urban Development Programs, A Handbook for Program Managers and Researchers' gives an example of an evaluation of a cooperative program in El Salvador that showed that the cooperatives enhanced the lives of the few families concerned but did not have a key impact 
on overall employment [10]. Bamberger [9] defines evaluation as "mostly used to assist in the selection and design of potential projects. Evaluation studies can gauge the point to which the project attained the intended impacts and the sharing of the benefits between different groups, and can appraise the cost-effectiveness of the project in comparison with other options."

Evaluation and monitoring systems are a helpful way to: Provide regular response on the level to which the projects are attaining their goals, spot likely problems at an early stage and recommend possible solutions, monitor the convenience of the project to all sectors of the intended population, monitor the effectiveness with which the various parts of the project are being implemented and recommend improvements, appraise the extent to which the project is able to realize its general objectives and offer guidelines for the development of future projects [9].

\subsection{Monitoring and Evaluation in Africa}

A Workshop organized by the Development Bank of Southern Africa- Operations Evaluation Unit, the African Development Bank- Operations Evaluation Department and the World Bank- Operations Evaluation Department in Johannesburg, 25-29 September 2000 on 'Monitoring and evaluation and the development challenge in Africa' postulated that the importance of the monitoring and evaluation (M\&E) function within public administration has been magnified by the 'growing voice of civil society', which has brought the question of good governance and better efficient public administration to the limelight [11]. The global drift towards more accountable, reactive and efficient government has bolstered the demand for M\&E capacity development, which has been the key focus of efforts to better governance in the context of a an all-inclusive development framework [11].

Evaluation has become increasingly important in Africa due to 'stagnant and negative economic growth rates', concern associated with governance and worries about the usefulness of development assistance [11].

\subsection{Monitoring and Evaluation Practice in Kenya}

In Kenya, as in most developing countries, monitoring and evaluation has yet to reach an acceptable level of operation [11]. However, there have been efforts to carry out some monitoring and evaluation. For example, in 1983, an M\&E was proposed for the District Focus for Rural Development strategy, and in the 1990s M\&E was used for poverty eradication strategy [12].

But on the ground, evaluations, when they are carried out, deal more with inputs and outputs than with impacts. Major evaluations are driven by activists and donor demands. There is a lack of professionalism on the part of qualified practitioners, and there are few academically trained evaluators. Those who carry out evaluations are influenced by social science research approaches and, because of their research background, carry out evaluations that in some cases do not have any of the characteristics of expert evaluation [11].

The most recent government effort at M\&E was the development of a National Integrated Monitoring and Evaluation System to monitor progress of the Economic Recovery Strategy. In most sectors within the government, there is no central monitoring and evaluation (M\&E) of programs and projects, except for financial auditing and monitoring that are done solely to audit and make submissions to the Ministry of Finance [11].

The support that evaluation can offer when used in the wider governance, institutional development and public segment reform is never fully understood. Issues such as poverty and government reforms and restructuring are presented as statistics, for example the number of programs that exist, or should be initiated to alleviate poverty; physical measures by the government such as privatizing parastatals, reducing the size of the civil service, curbing corruption, and discontinuing programs owing to cost-ineffectiveness; and non-evaluation interpretations of macro planning and budgetary reforms [11].

Evaluation statements are found in projects and government plans, but their function are not translated into program activities or operations, nor is evaluation appreciated as a useful and far-reaching tool in areas of human endeavour. Evaluation has not been formalized in the private sector, let alone the public sector [11].

\subsection{HIV/AIDS in Kenya}

Kenya like many other countries in Sub Saharan Africa has been brutally affected by HIV/AIDS since early eighties [1]. In 1984, the first holder of AIDS in Kenya was diagnosed [13]. Since then HIV/AIDS has been detected in all parts of the country. The impact of the HIV/AIDS on the population and on the entire economy has grown enormously over the years [13].

Efforts intended at minimizing transmission through contaminated blood, ensuring use of sterilized equipment, and scaling up programs aimed at stopping mother-to-child transmission of the virus have also been undertaken. All the same challenges still exist. These include the need for improved resource recruitment, the ever increasing figures of people in need of ART, the fight for resources for HIV/AIDS intervention with other health and developmental matters, the sluggish change of sexual behavioral patterns due to deep rooted cultural practices and values as well as the soaring level of poverty [1].

\subsubsection{National AIDS Control Council}

In respect of the challenges posed by the AIDS scourge the Government of Kenya established policy guidelines in the 'session Paper No. 4 of 1997 on AIDS in Kenya.'[13] AIDS was declared a national disaster in Kenya in 1999. A body to organize the harmonization of interventions, the National AIDS Control Council (NACC), was created as 'a corporate body under the State Corporations Act by a Presidential Order in Legal Notice No. 170 of $26^{\text {th }}$ 
September 1999' to provide leadership and coordinate a multi-sectoral response to the epidemic.[1]

Its functions include the development of policies, strategies and guidelines relevant to the prevention and control of AIDS. It was mandated to mobilize resources for AIDS control and prevention, to co-ordinate and provide framework for supervision of implementation of AIDS programmes, to collaborate with local and international agencies which work in AIDS control, facilitate the setting up of programmes on AIDS and develop national management information systems for AIDS control [1].

\subsubsection{The National HIV/AIDS Monitoring and Evaluation Framework}

National AIDS Control Council (NACC) [1] has developed a comprehensive National HIV/AIDS M\&E framework to coordinate stakeholders towards one agreed country-level monitoring and evaluation system. The goal of the M\&E framework is to establish a well coordinated, harmonised monitoring, evaluation and research system. This system is made-up to offer suitable and correct strategic information to direct the planning of the national response to HIV and AIDS in order to realize the objectives of KNASP.

The first KNASP was implemented in the (2000-2005). Its priority areas included prevention and advocacy, treatment, care and support, mitigation of the social-economic impact, monitoring and evaluation, and research; management and co-ordination of activities. It also emphasized on greater involvement of the civil and private sector organizations.

Lessons learnt led to the development of KNASP II (2005/6-2009/10).Its formation involved different stake holders and its aim was to "reduce the spread of HIV, improve the quality of life of those infected and affected, and mitigate the socio-economic impact of the epidemic"

A review of KNASP II (2005/6-2009/10) carried out between November 2008 and June 2009 showed various strengths and weaknesses in it. On the positive side, it showed that the information made available through the established M\&E system had a contribution to HIV programming and reviews.

On the negative side, the review found out that the National M\&E Framework was not well allied to KNASP II and not sufficiently incorporated in the planning process, there was inadequate information use in planning at decentralised levels because of incompetence, presence of parallel M\&E systems, inadequate data quality assurance systems, vital data not reported, and distribution of HIV M\&E information to stakeholders was untimely [1].

Therefore it was decided that a National HIV and AIDS Monitoring, Evaluation and Research Framework would be developed as one of numerous tools that would give support to the implementation of the new strategic plan, KNASP III.

\subsubsection{Best practices of the HIV/AIDS Monitoring and Evaluation Frame Work}

A broadened M\&E should be one that facilitates the correct collection, study and coverage of quality-assured data to help in decision-making at all levels, sharing of findings to all levels of policy makers and programme planners so as to inform planning of the national HIV response; monitoring of nationwide and programme indicators so as to agree on the progress made towards the set targets; harmonization of M\&E systems from shared, private and community levels within the national response to reinforce the 'One M\&E system'; Providing guidance and harmonization of all the monitoring and evaluation sub-systems to attain KNASP III targets and results; and to hold important partners to account for their agreed roles to warrant successful execution of the M\&E framework [1].

\subsubsection{NGOs Use of Monitoring and Evaluation in Kenya}

Among the main players in this fight against HIV/AIDS are civil society organizations, commonly known as NGOs. These organizations play a vital role of bringing HIV/AIDS services to the communities where the other organizations may not access or may not be efficient.

A critical challenge is that staff working outside the health sector is often unsure about what should be done, raising doubts as whether current knowledge concerning effective use of $M \& E$ is adequate [14]. In India, when external funding flooded the country, the HIV/AIDS

Strategies were adapted from the west without much consideration of the local diversity of culture and issues. This made monitoring of the programme challenging for the NGOs [15].

The increase in funding of HIV/AIDS programmes in Africa also raised the question of capacity of the NGOs to make the funds have a significant effect on fighting the epidemic and the affected people's lives [16].

\subsection{Knowledge Gap}

Across these various concerns lies a common need to recognize positive results and correct course as necessary These discussions have led to the conclusion that there is need to pay more attention to the usage of M\&E systems for project efficiency, effectiveness and impact. If you can't measure how well you are doing against targets and indicators, you may go on using resources, without changing the circumstances you have recognized as a problem at all.

A study by Mark Muzinda [17] on 'Monitoring and Evaluation Practices and Challenges of Gaborone based NGOs Implementing HIV/AIDS Projects in Botswana," determined that the monitoring and evaluation practices of the local NGOs in Gaborone fell short of the best practices. Most of the best practices were erratically performed and others were not done at all. Preparation for monitoring and evaluation was poorly and erratically done by respondents and implementing the $M \& E$ process was not effectively done by the respondents [17].

In Kenya, few researches have been carried out to establish the usage of the Monitoring and Evaluation systems in place. There is a need to find out how effectively the HIV/AIDS projects implemented by NGOs in Kenya are monitored and evaluated against the best monitoring and 
Evaluation practices as laid down by the current National HIV/AIDS Monitoring and Evaluation Research Framework (2009/10-2012/13)

\section{Research Methodology}

The researcher used interviews, questionnaires and observation as his research instruments. A sample of 24 project managers was interviewed while their assistants were given the questionnaires to fill. The data collected was analyzed using both quantitative and qualitative techniques. Measures of central tendency that is the mean, mode, and median were computed and interpreted.

\section{Data Analysis, Presentations and Interpretation}

\subsection{Introduction}

This chapter comprises of data analysis, presentation and interpretation of the findings. The data presented includes response rate, background information of the respondents and a presentation of findings against each individual objectives of the study. The data analyzed and presented was based on the responses to the items in the questionnaires schedules. Descriptive statistics are also used in analyzing the findings of this research project.

\subsection{Background Information}

\subsubsection{The Coverage of Services}

Table 4.1. Coverage of Services.

\begin{tabular}{lccc}
\hline Constituency & Frequency & Percent & $\begin{array}{l}\text { Cumulative } \\
\text { Percent }\end{array}$ \\
\hline Embakasi & 3 & 12.5 & 12.5 \\
Westlands & 3 & 12.5 & 25.0 \\
Kasarani & 3 & 12.5 & 37.5 \\
Starehe & 3 & 12.5 & 50.0 \\
Makadara & 12 & 50.0 & 100.0 \\
Total & 24 & 100.0 & \\
\hline
\end{tabular}

The analysis shows that, $12.5 \%$ of the respondents were from Embakasi Constituency, $12.5 \%$ from Westlands Constituency, $12.5 \%$ from Starehe Constituency and 50.0\% from Makadara Constituency. This is a good representation of the target population.

\subsubsection{The Date of NGOs Registered With NACC}

Table 4.2. Date of Organization Registered With NACC.

\begin{tabular}{llll}
\hline & Frequency & Percent & Cumulative Percent \\
\hline 2006 & 3 & 12.5 & 12.5 \\
2008 & 3 & 12.5 & 25.0 \\
2009 & 3 & 12.5 & 37.5 \\
2010 & 15 & 62.5 & 100.0 \\
Total & 24 & 100.0 & \\
\hline
\end{tabular}

The findings revealed that majority, $62.5 \%$ were registered in year 2010, while year 2009, 2008 and 2007 registered, $12.5 \%$ each. This shows that most of the NGOs have only been in operation for two years. This may affect their competence in the use of the Monitoring and Evaluation system.

\subsubsection{The Type of HIV/AIDS Projects Implemented by the NGOs}

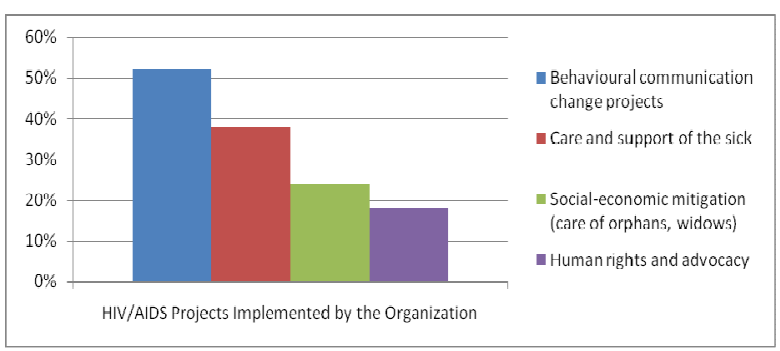

Fig 4.1. The Type of HIV/AIDS Projects Implemented by the NGOs.

The analyses reveal that, $52 \%$ of the NGOs implements behavioral communication change projects, where, $38 \%$ implements Care and support of the sick, 24\%, Social-economic mitigation (care of orphans, widows) and 18\% Human rights and advocacy

\subsubsection{The Duration the NGOs dealing with HIV/AIDS Projects have been in Existence}

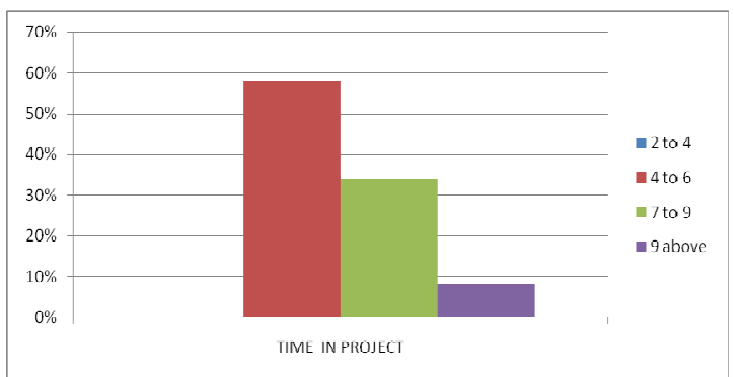

Fig 4.2. Duration the NGOs dealing with HIV/AIDS Projects have been in Existence.

The $58 \%$ of the NGOs have been implementing HIV/AIDS projects for 4-6years, $34 \%$ 7-9years and 8\% over 9years. This implies that the NGOs have been executing the projects for a long duration of time and therefore they are well positioned to provide adequate information to support the study and hence conclusion.

\subsubsection{NGOs Total Budget on HIV/AIDS Projects}

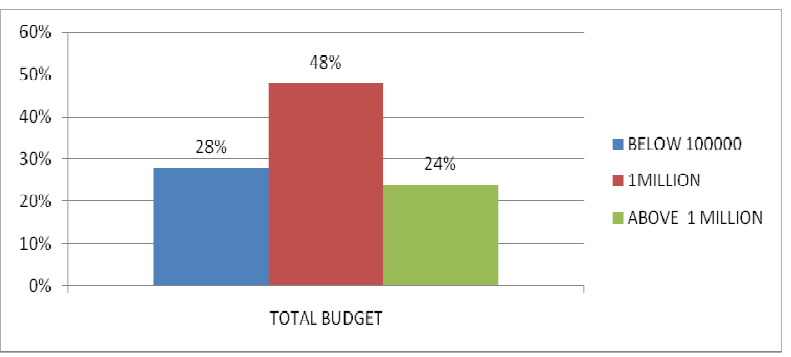

Fig 4.4. NGOs Total Budget on HIV/AIDS Projects

The $28 \%$ of the NGOs have a budget on HIV/AIDS 
projects of below shilling hundred thousands, $48 \%$ budget of up to shilling one million and $24 \%$ above shilling one million. This implies that the study has covered the various sizes of NGOs dealing with HIV/AIDS projects.

\subsubsection{The NGOs Source of Fund for HIV/AIDS Projects}

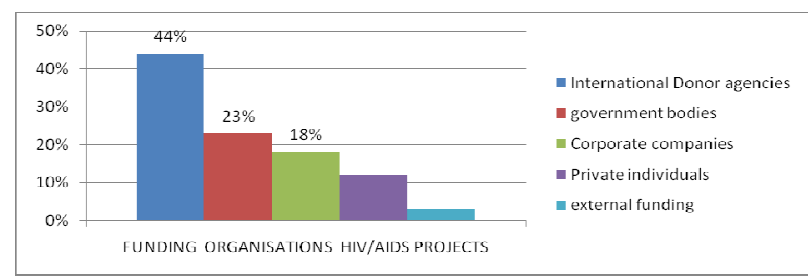

Fig 4.5. The NGOs Source of Fund for HIV/AIDS Projects.

The analyses reveal that, $44 \%$ of the NGOs get their funding from the International Donor agencies, $23 \%$ from the government bodies, $18 \%$ from Corporate companies, $12 \%$ from Private individuals and $3 \%$ do not get external funding. This means that International donors play a bigger role on the running of the NGOs and consequently the use of Monitoring and Evaluation.

\subsubsection{The Percentage of Donors Fund on the Total Budget on HIV/AIDS Projects}

From the chart, $14 \%$ of the NGOs have HIV/AIDS projects taking up to $25 \%$ of the budget, $32 \%$ takes up to $50 \%, 46 \%$ takes up to and $8 \%$ takes up $100 \%$ of the budget. This reflects that NGOs dealing with HIV/AIDS projects get enough donor support.

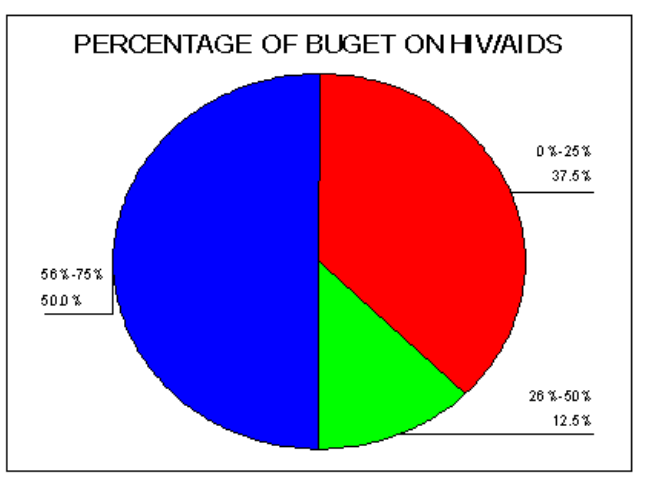

Fig 4.6. The Percentage of Donors Fund on the Total Budget on HIV/AIDS Projects.

\subsubsection{Staff Rates in the NGOs}

Table 4.3. Staff Rates in the NGOs.

\begin{tabular}{lll}
\hline & Percent & Cumulative Percent \\
\hline Less Than7 & 25 & 25 \\
$7-12$ & 12.5 & 37.5 \\
$13-18$ & 50 & 87.5 \\
Greater than 18 & 12.5 & 100 \\
Total & 100.0 & \\
\hline
\end{tabular}

The $25 \%$ of the organization have less than seven staff, $12.5 \%$ up to twelve, $50 \%$ up to eighteen and $12.5 \%$ above eighteen staff. This query reflects the size and the activity level in the NGOs .It also points out that there is enough man power to run the activities of the NGOs.

\subsection{The Monitoring and Evaluation Plan}

Table 4.4. Descriptive Statistics Monitoring and Evaluation Plan.

\begin{tabular}{|c|c|c|c|c|c|c|c|}
\hline \multicolumn{8}{|c|}{ Descriptive Statistics } \\
\hline & $\mathbf{N}$ & Range & Minimum & Maximum & Mean & Std. Deviation & Variance \\
\hline Conduct baseline & 24 & 1 & 4 & 5 & 4.75 & .442 & .196 \\
\hline A plan to guide $M \& E$ & 24 & 3 & 2 & 5 & 4.50 & 1.022 & 1.043 \\
\hline Reason not to have plan & 0 & & & & & & \\
\hline Donors involved in planning the $\mathrm{M} \& \mathrm{E}$ & 24 & 3 & 2 & 5 & 4.00 & 1.251 & 1.565 \\
\hline Staff involved in planning the $M \& E$ & 24 & 3 & 2 & 5 & 4.38 & 1.013 & 1.027 \\
\hline Community & 24 & 4 & 1 & 5 & 3.75 & 1.675 & 2.804 \\
\hline Beneficiaries & 24 & 4 & 1 & 5 & 3.13 & 1.727 & 2.984 \\
\hline Stakeholder not involved & 0 & & & & & & \\
\hline Data aspects & 24 & 1 & 4 & 5 & 4.87 & .338 & .114 \\
\hline Frequency of data collection & 24 & 4 & 1 & 5 & 3.25 & 1.595 & 2.543 \\
\hline Individuals in charge of $\mathrm{m} \& \mathrm{e}$ & 24 & 4 & 1 & 5 & 3.75 & 1.675 & 2.804 \\
\hline Schedule of M\&E activities & 24 & 4 & 1 & 5 & 4.00 & 1.769 & 3.130 \\
\hline Plan for dissemination of findings & 24 & 4 & 1 & 5 & 3.37 & 1.689 & 2.853 \\
\hline M\&E activities & 24 & 4 & 1 & 5 & 3.88 & 1.727 & 2.984 \\
\hline Percentage and evaluation & 24 & 1 & 1 & 2 & 1.13 & .338 & .114 \\
\hline Logical framework & 24 & 3 & 1 & 4 & 1.87 & 1.191 & 1.418 \\
\hline M\&E part of project schedule & 24 & 3 & 2 & 5 & 4.50 & 1.022 & 1.043 \\
\hline Disseminate monitoring and evaluation & 24 & 3 & 2 & 5 & 4.63 & 1.013 & 1.027 \\
\hline
\end{tabular}

From the table 4.4, the mean for NGOs conducting baseline data or condition of the community is 4.75 . This is close to 5 which is 'for all projects' on the likert scale. This suggests that many respondents felt that conducting a 
baseline study affects the effective use of monitoring and evaluation of projects in local NGOs dealing with HIV/AIDs in Kenya. It also has a very small standard deviation of 0.442 which suggests there is presence of uniformity in response among project managers in local NGOs managing these projects in Kenya.

Whether the organization has a plan to guide Monitoring and Evaluation at a scale of 4.50 indicates that there is a plan for almost all projects and a variance of 1.0 indicates that most of the respondents agree with the presence of a plan to guide $\mathrm{M} \& \mathrm{E}$.

The donors' involvement in planning the M\&E had a mean of 4.00 indicating that they were involved according to the majority response. On staff involvement in planning the M\&E, majority accepted this at a mean of 4.38.For the Community, majority of the respondents accepted as indicated by a mean of 3.75 though a big variance of 2.8 . While on beneficiaries, the respondents accepted as by a mean of 3.13 this implies for few projects.

Majority of the respondents on the question whether the data to be collected is specified for all the projects were positive, as indicated by a mean of 4.87 and variance of 0.11 . On the frequency of data collection, majority of the respondents felt this was 'for few projects' as indicated by mean of 3.25 . On the Individuals in charge of $M \& E$ this happened 'for some of the projects' at mean of 3.75, which is closer to 4 on the likert scale.

Whether there was a Schedule of M\&E activities, the findings reveal 'for some projects' as indicated by scale of 4.00.For the Plan for dissemination of findings a mean of 3.37 which is also closer to the 4 in the likert scale indicated 'for some of the projects' and M\&E activities have a mean of 3.88 which indicates for 'some of the projects'.

The researcher wished to establish the monitoring and evaluation cost as a percentage of the budget, majority of the respondents said it is not specified as indicated by a scale of 1.13 and variance of 0.11 .This will affect effective use of the Monitoring and Evaluation system because of inconsistency in finance. The result on the use of the Logical framework to carry out Monitoring and Evaluation was, 'for very few projects' indicated by a mean of 1.87.This points at incompetence on the part of the projects managers. It in turn affects effectiveness of the Monitoring and Evaluation System. Most of the respondents agreed that M\&E is part of project schedule as indicated by a mean of 4.5 which is 'for the most of the projects'. The majority of the respondents said that the dissemination of monitoring and evaluation findings is through report to the donors and newsletters

\subsection{Project Monitoring and Evaluation Process Implementation}

Table 4.5. Descriptive Statistics. Project Monitoring and Evaluation Process Implementation.

\begin{tabular}{|c|c|c|c|c|c|c|}
\hline & $\mathbf{N}$ & Range & Minimum & Maximum & Mean & Std. Deviation \\
\hline Compare Planned and Actual Budget & 24 & 3 & 2 & 5 & 3.88 & 1.191 \\
\hline Monitor and Control Activities & 24 & 5 & 0 & 5 & 3.25 & 1.824 \\
\hline Duration of comparing Schedules & 24 & 3 & 2 & 5 & 3.25 & 1.422 \\
\hline Monitor the use of Equipments & 24 & 3 & 2 & 5 & 4.00 & 1.251 \\
\hline Use Attendance Forms in Collecting data & 24 & 3 & 2 & 5 & 4.50 & 1.022 \\
\hline Use questionnaire in Collecting data & 24 & 3 & 2 & 5 & 4.00 & .885 \\
\hline Use Participant Observation in Collecting data & 24 & 3 & 2 & 5 & 4.25 & .989 \\
\hline Use in-depth Interview in Collecting data & 24 & 4 & 1 & 5 & 3.50 & 1.532 \\
\hline Use Registers in Collecting data & 24 & 4 & 1 & 5 & 3.63 & 1.610 \\
\hline Use group Interview in Collecting data & 24 & 4 & 1 & 5 & 4.00 & 1.251 \\
\hline Not Use Computers in Monitoring and Evaluation & 24 & 1 & 4 & 5 & 4.62 & .495 \\
\hline Interim Evaluation done in Implementation & 24 & 3 & 2 & 5 & 4.50 & 1.022 \\
\hline Summation Evaluation done in Implementation & 24 & 4 & 1 & 5 & 4.37 & 1.345 \\
\hline External Facilitators Involvement & 24 & 1 & 4 & 5 & 4.13 & .338 \\
\hline Documentation of Lessons & 24 & 4 & 1 & 5 & 4.38 & 1.345 \\
\hline
\end{tabular}

From the table 4.5, mean of NGOs that use comparison of planned and actual budget to monitor projects is 3.88 This is close to 3 which is 'for every 6 months' on the likert scale. This suggests that many respondents felt that many projects are monitored after every 6 months which is a major factor and this gives interim report to the donors hence if not done within the year it will affect the effective use of monitoring and evaluation of projects in local NGOs dealing with HIV/AIDs in Kenya. It also have a small standard deviation of 1.191 which suggests there is presence of uniformity in response among project managers in local NGOs in Kenya hence comparison of budgets is a major factor for project implementation managing these projects.

Monitor and Control Activities mean of 3.25 which is close to 3 indicates that it is after every 3 months according to the majority of the respondents. The Duration of comparing Schedules has scale of 3.3, which indicates that majority of them compare 'for a few projects' only. The Monitoring of the 
use of Equipments has a mean of 3.88 which is closer to 4, meaning that majority of the respondents never do this .This will affect the effectiveness of M\&E.

Use of Attendance Forms in collecting data has a mean of 3.25 mean which is close to 3 on the likert scale. Therefore, they use attendance forms for very few projects. This will have a negative effect on effective use of M\&E. on the 'Use questionnaire' in collecting data, the mean is 3.25.This means it is done for very few projects according to the majority of the respondents. Use of 'Participant Observation' in Collecting data has a mean of 4.00, which is closer to 4 on the liker scale a and hence they never do this according to majority of the respondents.

The use of in-depth Interviews in collecting data shows a 4.50 , means score which means majority of the respondents never it. Use of Registers in collecting data has a 4.0, mean score which is an indication that they never use them. Use group Interview in Collecting data has 4.25 mean is also never used according to the majority of the respondents.

The Use Computers in Monitoring and Evaluation which has 4.62 mean score is an indication that they use it for the storage of monitoring and evaluation data. Interim Evaluation done in Implementation 4.50 mean which indicates that they never do this as indicated by majority of respondents. Summation Evaluation done in Implementation 4.37 mean score also means that majority of the respondents never do this.

External Facilitators Involvement 4.13 is closer to 4 which means that they never carry evaluations and Documentation of Lessons with a mean of 4.38 meaning that placing it at never according to the majority of the respondents. It also have a small standard deviation of 1.191 which suggests there is presence of uniformity in response among project managers in local NGOs managing these projects in Kenya hence comparison of budgets is a major factor for project implementation.

\subsection{The Monitoring and Evaluation Environment of HIV/AIDS Projects}

From table 4.6, finance is always adequate and has a positive correlation of 0.229 . This suggests that availability of adequate finance for the project enhances implementation of monitoring and evaluation of HIV/AIDs projects positively. It has a p-value of 0.05 which suggests that it's a significant factor in the effective use of monitoring and evaluation in local NGOs dealing with HIV/AIDs in Kenya.

Whether the Donors Have Different Reporting Requirements has a positive correlation of 0.029 and p-value of 0.003 which suggest a very week relationship or rather the donor report have similar reporting requirements. While Monitoring and Evaluation Report Requirement from Donors has a positive correlation of 0.52 and $p$-value of 0.009 which suggest donors are strict on Monitoring and Evaluation Report Requirement. Demonstrating Long term
Impact to donor is rarely straight forward as indicated by a negative 0.667 and $p$ value of zero.

Table 4.6. Correlations of Monitoring and Evaluation Environment of HIV/AIDS Projects.

\begin{tabular}{|c|c|c|}
\hline $\begin{array}{l}\text { Monitoring and } \\
\text { evaluation process } \\
\text { implementation }\end{array}$ & & $\begin{array}{l}\text { Effective use of } \\
\text { monitoring and } \\
\text { evaluation system }\end{array}$ \\
\hline \multirow{3}{*}{$\begin{array}{l}\text { Finance Are Always } \\
\text { Adequate }\end{array}$} & Pearson Correlation & .229 \\
\hline & Sig. (2-tailed) & .021 \\
\hline & $\mathrm{N}$ & 24 \\
\hline \multirow{3}{*}{$\begin{array}{l}\text { Donors Have Different } \\
\text { Reporting Requirements }\end{array}$} & Pearson Correlation & .029 \\
\hline & Sig. (2-tailed) & .003 \\
\hline & $\mathrm{N}$ & 24 \\
\hline \multirow{3}{*}{$\begin{array}{l}\text { Monitoring and } \\
\text { Evaluation Report } \\
\text { Requirement From } \\
\text { Donors }\end{array}$} & Pearson Correlation & $.520 * *$ \\
\hline & Sig. (2-tailed) & .009 \\
\hline & $\mathrm{N}$ & 24 \\
\hline \multirow{3}{*}{$\begin{array}{l}\text { Demonstrating Long } \\
\text { term Impact }\end{array}$} & Pearson Correlation & $-.667^{* *}$ \\
\hline & Sig. (2-tailed) & .000 \\
\hline & $\mathrm{N}$ & 24 \\
\hline \multirow{3}{*}{$\begin{array}{l}\text { Collecting data on } \\
\text { HIV/AIDS not easy due } \\
\text { to stgma }\end{array}$} & Pearson Correlation & $.595^{* *}$ \\
\hline & Sig. (2-tailed) & .002 \\
\hline & $\mathrm{N}$ & 24 \\
\hline \multirow{3}{*}{$\begin{array}{l}\text { Lack of Monitoring and } \\
\text { Evaluation Expertis in } \\
\text { NGOs }\end{array}$} & Pearson Correlation & $.645^{* *}$ \\
\hline & Sig. (2-tailed) & .004 \\
\hline & $\mathrm{N}$ & 24 \\
\hline
\end{tabular}

*. Correlation is significant at the 0.05 level (2-tailed).

**. Correlation is significant at the 0.01 level (2-tailed).

The analysis reveals that Collecting data on HIV/AIDS not easy due to stigma indicated by a negative 0.595 and $p$ value of 0.02 . Where the majority of the respondent agreed that there is lack of monitoring and evaluation expertise in NGOs positive correlation of 0.645 and $p$ value of 0.004 .

\subsection{The One Sample Test}

The H0, states that the project managers in local NGOs running HIV/AIDS projects in Kenya do not effectively use the monitoring and evaluation system as laid down in the M\&E framework of the current KNASP III.

Since the t- test $(23 \mathrm{df})$ is greater than the tabulated i.e. t.95=1.71 for all monitoring and evaluation environment we accept the $\mathrm{H}_{0}$ :

Thus H0.Project managers in local NGOs running HIV/AIDS projects in Kenya do not effectively use the monitoring and evaluation system as laid down in the M\&E framework of the current KNASP III. 
Table 4.7. One Sample Test.

\begin{tabular}{|c|c|c|c|c|c|c|}
\hline \multirow{3}{*}{$\begin{array}{l}\text { Monitoring and evaluation } \\
\text { environment }\end{array}$} & \multicolumn{6}{|c|}{ Test Value $=0$} \\
\hline & \multirow[b]{2}{*}{$\mathrm{t}$} & \multirow[b]{2}{*}{ df } & \multirow[b]{2}{*}{ Sig. (2-tailed) } & \multirow[b]{2}{*}{ Mean Difference } & \multicolumn{2}{|c|}{$\begin{array}{l}\text { 95\% Confidence Interval of the } \\
\text { Difference }\end{array}$} \\
\hline & & & & & Lower & Upper \\
\hline Finance Are Always Adequate & 11.826 & 23 & .000 & 2.875 & 2.37 & 3.38 \\
\hline $\begin{array}{l}\text { Donors Have Different Reporting } \\
\text { Requirements }\end{array}$ & 45.816 & 23 & .000 & 4.625 & 4.42 & 4.83 \\
\hline $\begin{array}{l}\text { Monitoring and Evaluation Report } \\
\text { Requirement From Donors }\end{array}$ & 22.151 & 23 & .000 & 4.000 & 3.63 & 4.37 \\
\hline Demonstrating Long term Impact & 23.806 & 23 & .000 & 3.875 & 3.54 & 4.21 \\
\hline $\begin{array}{l}\text { Collecting data on HIV/AIDS not } \\
\text { easy due to stigma }\end{array}$ & 14.568 & 23 & .000 & 3.375 & 2.90 & 3.85 \\
\hline $\begin{array}{l}\text { Lack of Monitoring and } \\
\text { Evaluation Experts in NGOs }\end{array}$ & 14.568 & 23 & .000 & 3.375 & 2.90 & 3.85 \\
\hline
\end{tabular}

\subsection{Testing the Hypothesis}

The $\mathrm{H}_{0}$ states that Project managers in local NGOs running HIV/AIDS projects in Kenya do not effectively use the monitoring and evaluation system as lay down in the M\&E framework of the current KNASP III. This was found to be valid for all the monitoring and evaluation of the environment as indicated by table 4.7 .

\section{Summaries of the Major Findings}

According to the findings, most of the services were found in makadara constituency with over $50 \%$ as indicated by table 4.1. Majority of the registration was done in the year 2010 where $62.5 \%$ of them were registered with NACC which indicated a big increase in number as indicated by the table 4.2. The findings also show that the type of the HIV/AIDS implemented by the organizations $52 \%$ of these organizations concentrated on the behavioural communication change projects as indicated by fig 4.1.only $18 \%$ were concerned with the human rights and advocacy.

According to the study revelations the majority of the have been in place for $4-6$ years which is indicated by $58 \%$ on fig 4.2.only $8 \%$ of them have had more than 9 years of existence. It is also found out that majority had more that Ksh 100,000 for their budget according to the fig 4.4.

These funding of most of these organizations comes from the $\mathrm{CCO}$, which helps them to fund these projects as indicated by $63 \%$ on fig 4.5 . The study also reveals that the percentage of the donor funds on the budget on HIV /AIDS projects was $50 \%$ as indicated by fig 4.6. There are also employees of these organization which as shown by table $4.337 .5 \%$ have $7-12$ while $37.5 \%$ of them also have $13-18$ staff members.

From the table 4.4 the mean for conducting data is 4.75 which therefore indicate that it has a lot of effect in evaluation of these projects. The findings from the table 4.5 the mean for the organizations using comparison of planned data and actual data when monitoring projects is 4.2 and 3.88 respectively which means that they conduct this exercise after every 6 months. When conducting and evaluating the environment at which the HIV/AIDS projects are located indicates that there is adequate finances which enhances the implementation of this and it is usually effective .

\section{Conclusions}

From the findings of the study we could deduce that the there are adequate services being offered in the country which have a lot of experience in this work with regard to the number of years they have been in plac. Their work has also led to more people appreciating their services that is why there is a record growth in the registrations.

Most of them however have given a lot of weight to the behavior change and have as compared to the human rights. The donors have played a vital role in enabling the survival of these organizations through funding their projects. The Monitoring and evaluation plan has also been a success with stakeholders being involved in the planning. the Project monitoring and evaluation process implementation has helped in ensuring that the funds are properly used and the staff has adequate training to enable them tackle health issues. These have helped reduce the challenges being faced by these projects. The monitoring and evaluation environment of HIV/AIDS projects in Africa has also increased in implementation in order to make it more effective and therefore make the funds have a significant impact on the fight against the epidemic also those who are affected.

\section{Recommendations}

The governments should not leave the burden to the NGO shoulders but should also actively participate in trying to eradicate this disease among its citizens. They should also facilitate the environment that these NGO work in and ensure adequate security to the staff. The M\&E should also be broadened to ensure that there is effective collection, study and coverage of quality data for evaluation of these NGOs. The human rights and advocacy should also be taken 
into consideration because it could help in reduction of stigma among those infected by this disease enabling them to live their lives well.

\section{Suggestion for Further Study}

The study objective was to establish the status of effective use of Monitoring and Evaluation in NGOs dealing with the HIV/AIDS pandemic in Kenya. The researcher feels that Monitoring and Evaluation can form a rich area for further studies, as Monitoring and Evaluation is an indispensable tool in quality service provision especially in the health industry.

\section{References}

[1] National AIDS Control Council: National HIV/AIDS Monitoring, Evaluation and Research Framework (2009/10-2012/13) December 2009, Available at www.nacc.or.ke/.../171/KNASP\%20III\%20M\&E\%20Frame work.pdf, accessed on23/03/2011.

[2] Planning and control systems available at http://www-project.slac.stanford.edu/ilc/planning/resources/ controlsyst.html accessed on 21/1/2011.

[3] R, Stacey, Complex Responsive Process in Organizations: Learning and Knowledge Creation, London, Routledge,,2001 http://www.plexusinstitute.org/resource/collection/5FD4AC EF-7B50-4388-A93E-109B0988049F/Intro_to_CRP_Such man_ACFB945.PDF. accessed on 20/01/2011.

[4] S, Cicmil, and D, Hodgson, Making Projects Critical, Basingstoke, Palgrave Macmillan, ,2006. Available at http://www.palgrave.com/products/Title.aspx?pid=269522. accessed on $20 / 01 / 2011$.

[5] Lavagnon A. Ika, Amadou Diallo, Denis Thuillier," Project management in the international development industry: The project coordinator's perspective", International Journal of Managing Projects in Business, Vol. 3 Issue: 1,2010, pp.61

[6] Abdullah A. Hamdok 'Monitoring and evaluation and the development challenge in Africa' Seminar and workshop. Johannesburg, 25-29 September 2000,p,23 http://www.afdb.org/fileadmin/uploads/afdb/Documents/Eva luation-Reports/00788446-FR-ECD-JOHANNESBURG-20 00.PDF accessed on 21/12/2010

[7] Michael, Bamberger and Eleanor, Hewitt, Monitoring and Evaluating Urban Development Programs, A Handbook for Program Managers and Researchers, Washington, D.C, World Bank Technical Paper no 53,1986,p54http://web.mit.edu/urbanupgrading/upgrading/is sues-tools/tools/monitoring-eval.htmlaccessed $21 / 12 / 2010$

[8] Janet Shapira, Monitoring and Evaluation, http://www.civicus.org/new/media/Monitoring\%20and\%20 Evaluation.pdf accessed on 07/12/2011.

[9] Michael, Bamberger and Eleanor, Hewitt, Monitoring and Evaluating Urban Development Programs, A Handbook for Program Managers and Researchers, Washington, D.C, World Bank Technical Paper no 53,1986,p54http://web.mit.edu/urbanupgrading/upgrading/is sues-tools/tools/monitoring-eval.htmlaccessed on $21 / 12 / 2011$.

[10] Jaap Koot, Monitoring and Evaluation for NGOs in Health and AIDS Programmes, available at www.phc-amsterdam.nl/index.php?hid

[11] Karen T. Odhiambo Monitoring and evaluation and the development challenge in Africa' Seminar and Workshop organized by the Development Bank of Southern Africa, Johannesburg, $\quad 25-29 \quad$ September 2000,p57http://www.afdb.org/fileadmin/uploads/afdb/Docu ments/Evaluation-Reports/00788446-FR-ECD-JOHANNES BURG-2000.PDF accessed on 21/12/2010.

[12] Ministry of State for Planning, National Development and Vision 2030,National Intergrated Monitoring \&Evaluation Systems. Available at http://www.monitoring.go.ke accessed on $07 / 12 / 2011$.

[13] National AIDS Control Council: National HIV/AIDS Monitoring and Evaluation Framework, (2005/6-2009/10) December2005, p, 2.At www.nacc.or.ke/.../171/KNASP\%20III\%20M\&E\%20Frame work.pdf.accessed on 23/03/2011.

[14] Joana White \&John Morton, Mitigating Impacts of HIV/AIDS on Rural Livelihoods: NGOs Experience in Sub-Saharan Africa. Development in Practice Journal, vol. 15, No.2 April 2005, p187. http://www.jstor.org/pss/4030079 accessed on 11/01/2011.

[15] N.S Deadhar, 'Review of National HIV/AIDs control programme in India with a view of making it community oriented, more effective \& sustainable', Journal of Public Health Policy, vol. 24,no,2,2003 p159.

[16] Caroline Halmshaw \& Kate Hawkins, 'Capitalising on Global HIV/AIDS Funding: The Challenges for Civil Society \& Government', Journal of Reproductive Health Matters, Vol. 12 , no. $24, \mathrm{p} 35$

[17] Mark, Muzinda. "Monitoring and evaluation practices and challenges of Gaborone based local NGOs implementing HIV/AIDS projects in Botswana." (2007). 